\title{
REORGANIZAÇÃO DOS SISTEMAS AGROALIMENTARES CULTIVÁVEIS NO MUNICÍPIO DE PORTO DA FOLHA/SE
}

José Natan Gonçalves da Silva ${ }^{1}$ Sônia de Souza Mendonça Menezes²

Resumo: As tecnologias agrícolas, regidas pelo agronegócio, também avançam sobre as unidades de produção familiar, provocando a padronização das cadeias produtivas e a dissolução da autossuficiência agroalimentar das famílias rurais. Nesse sentido, este artigo tem como objetivo analisar as modificações nos sistemas agrícolas e alimentares dos agricultores familiares do município de Porto da Folha/SE. A metodologia efetivada baseia-se na leitura de referenciais teóricos, na análise de dados secundários e em pesquisas de campo. Os resultados da pesquisa apontam para a fragmentação da diversidade produtiva da agricultura familiar, conjuntura refletida no comprometimento da preservação dos recursos genéticos cultiváveis e na manutenção dos hábitos alimentares dos agricultores familiares.

Palavras-chave: Agronegócio. Modernização da agricultura. Agricultura familiar. Cultivos tradicionais. Alimentação.

\section{REORGANIZATION OF AGRIFOOD SYSTEMS CULTIVABLE IN THE MUNICIPALITY OF PORTO DA FOLHA/SE}

Abstract: Agricultural technologies governed by agribusiness, also advance on family production units, leading to the standardization of the productive chains and the dissolution of the self-sufficiency agrifood of the rural families. In this sense, this article aims to analyze the changes in the agricultural and food systems of the family farmers of the municipality of Porto da Folha/SE. The methodology implemented is based on the reading of theoretical references, the analysis of secondary data and in field surveys. The results of the research point to the fragmentation of the productive diversity of family agriculture, situation reflected in the commitment to conservation of genetic resources cultivable and maintaining the eating habits of family farmers.

Keywords: Agribusiness. Modernization of agriculture. Family farming. Traditional crops. Alimentation.

\section{REORGANIZACIÓN DE LOS SISTEMAS AGROALIMENTARIOS CULTIVABLES EN EL MUNICIPIO DE PORTO DA FOLHA/SE}

Resumen: Las tecnologías, regidas por el agronegocio, también avanzan sobre las unidades de producción familiar, provocando la estandarización de las cadenas productivas y la disolución de la autosuficiencia agroalimentaria de las familias rurales. En este sentido, este artículo tiene como objetivo analizar las modificaciones en los sistemas agrícolas y alimentarios de los agricultores familiares del municipio de Porto da Folha/SE. La metodología efectiva se basa en la lectura de referenciales teóricos, en el análisis de datos secundarios y en investigaciones de campo. Los resultados de la investigación apuntan a la fragmentación de la diversidad productiva de la agricultura familiar, coyuntura reflejada en el compromiso de la preservación de

\footnotetext{
${ }^{1}$ Universidade Federal de Sergipe, Programa de Pós-graduação em Geografia, São Cristóvão/SE, Brasil, natanufs@gmail.com, https://orcid.org/0000-0002-1776-9655

2Universidade Federal de Sergipe, Departamento de Geografia, São Cristóvão/SE, Brasil, soniamendoncamenezes@gmail.com, https://orcid.org/0000-0001-6072-771X
} 
los recursos genéticos cultivables y en el mantenimiento de los hábitos alimentarios de los agricultores familiares.

Palabras clave: Agronegocio. Modernización de la agricultura. Agricultura familiar. Cultivos tradicionales. Alimentación.

\section{Introdução}

As transformações das relações produtivas no campo, alicerçadas na modernização das cadeias agrícolas, têm aguçado novos olhares e dilemas em torno da exploração predatória dos bens ecológicos, uso intensivo de insumos, perda de recursos genéticos cultiváveis e fragmentação de hábitos alimentares.

Conforme Cavalcanti (2004) e Arnaiz (2005), a produção de alimentos está inserida na lógica de mercado globalizado, influenciada pelos objetivos e decisões tomadas por um seleto grupo de corporações transnacionais, produtoras de insumos mecânicos, químicos e biotecnológicos, que controlam o mercado de distribuição e comercialização de alimentos. Tais oligopólios atuam na fragmentação das práticas tradicionais e alternativas de produção (artesanal, cooperada, orgânica e agroecológica) alicerçadas nos territórios e reproduzidas in loco, comprometendo a autonomia dos agricultores no domínio sobre os meios de produção e na autossuficiência agroalimentar.

Nesse sentido, este artigo tem como objetivo analisar as transformações dos sistemas agroalimentares reproduzidos por agricultores familiares do município de Porto da Folha/SE, antevendo para a inter-relação da modernização/padronização da agricultura, a perda de recursos genéticos cultiváveis e a alteração dos hábitos alimentares.

A metodologia utilizada consistiu em revisões da literatura, levantamento de dados estatísticos, pesquisas de campo e aplicação de entrevistas semiestruturadas junto a 70 agricultores familiares residentes em 58 comunidades situadas no espaço rural. O quantitativo de entrevistas resulta de uma amostra fundamentada na metodologia snowball (VINUTO, 2014). A técnica consiste na utilização de informantes-chaves, que indicam a localização de pessoas situadas dentro de uma população geral e com perfil necessário à execução da pesquisa. Em seguida, as pessoas indicadas apontam novos contatos através da sua rede pessoal que, sucessivamente formam cadeias de referência e o quadro de amostragem de interesse do pesquisador. O número de entrevistados adequou-se aos pressupostos definidos na técnica da "bola de neve", ou seja, a saturação da amostragem ocorreu 
à medida que os novos nomes indicados não traziam novas informações ao quadro de análise.

As transformações nas relações produtivas e nos sistemas agroalimentares suscitam questionamentos sobre a dinâmica da agricultura familiar, mais especificamente do município de Porto da Folha e do sertão sergipano: a "modernização" de unidades de produção familiar está alinhada aos paradigmas difundidos pelo agronegócio? A padronização das atividades agrícolas e o uso intensivo de insumos implicam na autonomia dos agricultores familiares frente os processos produtivos? Em que medida a fragmentação das práticas agrícolas tradicionais alteram os hábitos associados à manipulação, ao armazenamento e ao consumo de alimentos arraigados no território?

Buscando o aguçamento do debate a partir das questões apontadas, o artigo segue estruturado com a problematização da temática lastreada em abordagens teóricas sobre a modernização da agricultura e os impactos do agronegócio sobre as cadeias agrícolas internacionais. Na sequência são realizadas as discussões acerca da reorganização dos sistemas agroalimentares de unidades de produção familiar no município de Porto da Folha e, por fim, são tecidas as considerações finais.

\section{A modernização da agricultura e os impasses sobre os regimes agroalimentares}

A origem dos sistemas internacionais agroalimentares confunde-se com 0 desdobramento da Revolução Industrial no século XVIII. Conforme Ramos (2018), a partir do ano de 1850 as atividades agrícolas e os regimes alimentares são inseridos em formas sistêmicas de integração e organização global da agricultura. Esse processo, iniciado na Inglaterra, está fundamentado na mecanização e na inserção da mão de obra assalariada na agricultura.

O alinhamento do progresso técnico com as atividades agrícolas tem como propósitos aumentar a capacidade produtiva das pessoas empregadas, potencializar a exploração dos recursos naturais e, consequentemente reduzir o tempo de trabalho investido na produção de determinado gênero agrícola (GRAZIANO DA SILVA, 1999). Sendo assim, a introdução de máquinas, instrumentos mais aperfeiçoados e a racionalização dos grandes sistemas agroalimentares buscam aliar dois elementos imprescindíveis na acumulação do capital: o estímulo à produtividade e a elevação dos lucros. 
Friedmann (1982) destaca que após a Revolução Industrial são definidos basicamente dois regimes agroalimentares internacionais. O primeiro situado entre 1870 e 1930 está em consonância com a ideia de livre comércio, que privilegia em escala global a produção de grãos. O processo de urbanização implica ainda em mudanças significativas na dieta e nas escolhas alimentares da população. $O$ segundo regime é identificado entre os anos de 1945 e 1970, marcado pelos colapsos do comércio internacional decorrentes das crises do século XX. Além disso, nota-se a tendência de protecionismo europeu, que redireciona as famílias rurais o papel da produção de alimentos.

Durante o segundo regime agroalimentar também se observa em países desenvolvimentos - cujo principal representante é os Estados Unidos - e, logo depois, nos países subdesenvolvidos, o investimento em tecnologias voltadas ao desenvolvimento e ao aprimoramento de insumos mecânicos, químicos e, mais recentemente biológicos e informatizados, destinados ao aumento da produtividade de alimentos em menor espaço e escala de tempo.

Esse contexto, na perspectiva de Matos e Pessôa (2011), está associado à lógica de produção capitalista, cujo modelo de modernização do campo apresentouse significativamente excludente, concentrador e conservador. A ideia de desenvolvimento postulada ao espaço rural estava restringida a produção e o crescimento da agropecuária era o principal indicador de desenvolvimento econômico. Tal processo marcado pelo uso intensivo de máquinas, agroquímicos e insumos biológicos consiste o principal sustentáculo de desenvolvimento dos sistemas agroalimentares.

Conforme Altieri (2004), na segunda metade do século XX vários países latino-americanos, a exemplo do Brasil, engajaram-se nas modificações das cadeias produtivas do campo, com base no paradigma da Revolução Verde, a princípio proposto e implementado nos países desenvolvidos. O autor enfatiza que a adesão a esse modelo teve como meta o aumento da produtividade das atividades agropecuárias, assentadas no uso intensivo de insumos químicos, na mecanização, na irrigação, no melhoramento genético dos animais e de variedades de sementes de alto rendimento. Alinhado a esse contexto, nota-se a criação de políticas públicas nacionais embasadas no crédito agrícola subsidiado, na pesquisa e na extensão rural.

A modernização das cadeias produtivas no campo está alicerçada na lógica de produção que visualiza o campo sob o domínio das atividades agrícolas, espaço 
e condições favoráveis a exploração e a transformação através de mecanismos pautados no emprego da alta tecnologia e na racionalidade dos mercados (MOREIRA, 2003). Desse modo, a consolidação do capitalismo moderno no campo ocorre mediante a superação das formas primitivas artesanais de manejo e produção de alimentos.

Trata-se de um contexto que, na análise de Graziano da Silva (1998), remonta a dois processos: um de destruição da economia natural, pela retirada progressiva dos vários camponeses que asseguravam a "harmonia" da produção assentada na relação homem-natureza (e suas contradições); e o outro, de uma nova síntese, de recomposição de outra "harmonia" - também permeada por novas contradições -, baseada no conhecimento, no controle cada vez maior sobre a natureza e na possibilidade da reprodução artificial das condições naturais da produção agrícola. A esta passagem Graziano da Silva (1998) denomina de industrialização da agricultura.

O processo de industrialização das atividades agrícolas tem sua origem vinculada à cidade, ou seja, o crescimento dos centros urbanos, cuja produção e trabalho concentrados na indústria e, posteriormente, nos serviços, pressionam a transformação das cadeias agrícolas mediante a adesão à moderna tecnologia com vistas à elevação da produtividade. Na perspectiva de lanni (1997), o aumento prodigioso da população concentrada nos centros urbanos configura elemento imprescindível na reorganização social do trabalho e na produção do espaço rural.

Para Graziano da Silva (1981) a industrialização da agricultura configura um processo de conversão do campo em uma fábrica, ou seja, a agricultura deixa de ser um "setor autônomo" e transforma-se em um ramo da própria indústria subordinada ao capital que, no caso específico do Brasil, posteriormente irá consolidar a formação dos Complexos Agroindustriais (CAls).

Na concepção de Marafon (2011) a constituição dos CAls tem como contexto a integração intersetorial entre a agricultura e a indústria. Resulta desse contexto a criação de indústrias processadoras de alimentos e produtoras de insumos agrícolas, agora internalizadas na economia nacional. Por sua vez, a consolidação dos CAls é fomentada pelo capital financeiro, basicamente por meio da institucionalização do Sistema Nacional de Crédito Rural (SNCR) e das políticas de agroindustrialização derivadas dos fundos de financiamentos governamentais.

A reorganização das cadeias agropecuárias do Brasil sempre esteve voltada para o mercado externo. Para Matos e Pessôa (2011), esse processo ocorre através 
da adoção de inovações tecnológicas viabilizada pela integração do capital industrial, dos grandes e médios proprietários de terra e, principalmente, por intermédio do Estado.

Convergindo com a abordagem anterior, Marafon (2011) ressalta que os CAls no Brasil são caracterizados pela utilização da tecnologia, da mecanização da produção e da incorporação de vastas extensões de terra para o desenvolvimento das grandes cadeias produtivas como a soja, o café, o algodão e a pecuária bovina, destinadas primordialmente à exportação. Tais complexos produtivos são formados por meio da introdução da lógica capitalista no campo, que tem a capacidade de transformar a produção agrícola em agronegócio.

Brandão (2007) menciona que a racionalidade empresarial constitui processo dominante nos diferentes cenários da vida social e econômica da cidade e do campo. Esse contexto se traduz na configuração do agronegócio, cujas estruturas de poder se apropriam dos espaços de vida, trabalho e produção. Tal racionalidade está "centrada no lucro, na competência especializada e na competição legitimada como uma forma quase única de realização do 'progresso'” (BRANDÃO, 2007, p.39). O avanço desse modelo de produção alimentado pelo capitalismo exploratório e traduzido na estrutura do agronegócio corrompe práticas, visões de mundo e vivências tradicionais que, até recentemente, ditavam as relações do tempo-espaço de comunidades rurais.

O agribusiness é materializado à medida que agricultura é transformada em cadeia produtiva através de um contexto sistêmico, que na visão de Moraes (2013) integra operações de produção, biotecnologia, distribuição de insumos, armazenagem, processamento e distribuição de produtos agrícolas e semielaborados industriais. Portanto, ele compõe-se de sistemas e cadeias agroalimentares e agroindustriais, inseridas em uma rede de conglomerados e empresas transnacionais que alteram diferentes sistemas naturais e agroecossistemas cultiváveis. O estímulo ao desenvolvimento desses setores é assegurado por aparatos políticos, normativos e pela atuação de instituições e organizações de crédito, pesquisa, assistência técnica e publicidade.

O avanço das especializações tecnológicas e produtivas no campo encontrase dominada pelo agronegócio, que visa exclusivamente 0 aumento da produtividade e à elevação dos lucros. Diante disso, grandes corporações transnacionais ligadas ao agrobusiness e apoiadas em laboratórios de pesquisa 
criam novos insumos (químicos, biológicos, mecânicos e informatizados) capazes de reduzir o ciclo natural dos cultivos agrícolas e da produção animal.

Conforme Graziano da Silva (1999), a introdução das inovações tecnológicas reduz substancialmente o tempo de trabalho e de não trabalho na agropecuária. $A$ diminuição do tempo de trabalho pode ocorrer com a mecanização e a quimificação do processo produtivo, como a utilização dos tratores e herbicidas, que anulam, respectivamente, a necessidade do preparo do solo e da capina de forma manual, procedimento que demandava mais tempo. Por sua vez, o tempo de não trabalho, considerado por Graziano da Silva (1999) um prolongamento não rentável da produção (período de crescimento da plantação, por exemplo), pode ser reduzido através de alterações genéticas das sementes ou mesmo com o uso de adubos químicos, capazes de diminuir o ciclo vegetativo natural dos cultivos.

No atual processo de globalização, Cavalcanti (2004) enfatiza que o uso da moderna tecnologia compreende elemento imprescindível nos sistemas de produção agroalimentar, implicando mudanças nos processos produtivos, nos sujeitos envolvidos e, consequentemente nos territórios. A autora adverte que a tendência à especialização tecnológica insere-se em um contexto da globalização, que articula o campo à dinâmica mundial em esferas transescalares. Essa relação modifica as estruturas socioeconômicas pré-existentes, reconfigura os sistemas produtivos e altera os hábitos alimentares.

lanni (1997) menciona que as grandes corporações da agropecuária e do agrobusiness induzem, organizam e determinam os sistemas de produção, comercialização e consumo. Tais transnacionais articuladas com os processos de marketing influenciam ainda os padrões de alimentação, que atendem às necessidades reais e imaginárias dos indivíduos. As dinâmicas de mercado intrínsecas ao território, por vezes, são modificadas ou substituídas. Os agricultores familiares são sujeitados por essas corporações a processos produtivos específicos, algo que compromete a legitimidade do grupo que, não raro, perde a autonomia de produzir seus próprios alimentos, necessários à reprodução socioeconômica e cultural da família.

Na concepção de Boucher (2006) os processos de globalização tem marcado um novo cenário econômico, traduzido na liberalização do comércio internacional e nos intensivos investimentos privados, reordenando a estrutura do mercado em torno das cadeias agroalimentares. Trata-se de uma nova governança postulada pelas empresas transnacionais, que impõem novos padrões produtivos e 
alimentares sobre produtores e consumidores. Se no passado os mercados locais eram autogeridos pelos atores pertencentes ao território, atualmente eles têm se convertido aos ditames da globalização, que padroniza os processos produtivos, expande os canais de distribuição, através das redes de supermercados, e uniformiza hábitos e escolhas alimentares.

Os sistemas agroalimentares encontram-se transformados pela lógica capitalista, emaranhados pela atuação de empresas, corporações e conglomerados agroindustriais. Trata-se de "núcleos ativos e predominantes, articulando atividades produtivas e mercados, geopolíticas mercantis e marketings, modalidades de produtos e ondas de consumismo" (IANNI, 1997, p. 40), cuja organização da produção e do trabalho é regulada, sobretudo, pelo capital estrangeiro e interesses de multinacionais, que transcendem os limites territoriais do Estado.

A padronização da agricultura através de processos produtivos e tecnológicos apresenta desenvolvimento radical por meio da uniformização da produção, distribuição e comercialização de alimentos no mercado globalizado, controlado e dominado por oligopólios associados ao agronegócio, cuja produção de alimentos, mesmo "atendidas" as normativas de certificação, passa a ter qualidade questionável.

A crise ecológica motivada pela modernização da agricultura diante da má gestão dos recursos naturais, bem como, a desconfiança de consumidores em torno de alimentos agrícolas, semielaborados e industrializados, que perderam seu referencial de origem, possibilitaram a emergência de um novo padrão de consumo associado a movimentos alternativos, que reivindicam a produção e a comercialização de alimentos saudáveis, naturais e artesanais, inseridos em modelos sustentáveis de produção e que estejam alinhados ao comércio justo, a manutenção do know-how, a preservação do patrimônio ambiental e cultural e apresentem padrões de qualidade atrelados a origem do produto.

Com base nas discussões realizadas por Costa (2003) e Anjos e Caldas (2017), a qualificação do produto através do referencial de origem consiste exigência crescente nas redes de consumidores. Tal fato se deve a relevância do alimento como fato social, ou seja, alimentar-se supera a mera satisfação das necessidades imediatas. $\mathrm{O}$ ato de comer conjuga valores e significados que buscam a afirmação da identidade e perpassa pela tomada de consciência acerca da importância do consumo de alimentos saudáveis e o uso sustentável dos recursos naturais. Tratase da constituição de consumidores, que passam a rever seus hábitos alimentares 
por meio de mecanismos de reflexão sobre o alimento a ser consumido e os valores imbricados no produto.

Arnaiz (2005) ao apresentar indicativos da configuração da nova ordem mundial alimentar retrata que, atualmente a produção de alimentos primazia às exigências do mercado, abalizado por ciclos econômicos capitalistas de grande escala que, entre outros aspectos, supõem a intensificação da produção agrícola, a orientação da política de oferta e a demanda de determinados alimentos, concentrados em negócios executados pelas empresas multinacionais, que difundem a lógica da internacionalização da alimentação.

Constata-se que os grandes sistemas de produção agroalimentar são marcados pela "intensificação da agricultura, padronização dos alimentos e por processos que se desenvolvem através de cadeias longas, governadas por grandes corporações e complexos agroindustriais que operam à escala planetária" (ANJOS; CALDAS, 2017, p. 2).

Tais imposições do mercado, apontadas por Anjos e Caldas (2017), influenciam na modificação ou na substituição de práticas agrícolas e hábitos alimentares arraigados à identidade dos grupos sociais. Esse cenário encontra-se difundido entre segmentos da agricultura familiar no sertão sergipano e, mais especificamente, no município de Porto da Folha, dinâmicas que serão discutidas nas abordagens subsequentes.

\section{Monocultivo do milho em terras sertanejas: fragmentação da diversidade agrícola e dos hábitos alimentares}

O município de Porto da Folha/SE está situado no Território do Alto Sertão Sergipano (Mapa 1). Com 27.146 habitantes, dos quais, residindo: 63,33\%, no campo; e 36,7\%, no espaço urbano (IBGE, 2010), o município tem, na agropecuária um dos principais sustentáculos da reprodução social e econômica de sua população. 
MAPA 1: LOCALIZAÇÃO DO RECORTE EMPÍRICO DA PESQUISA

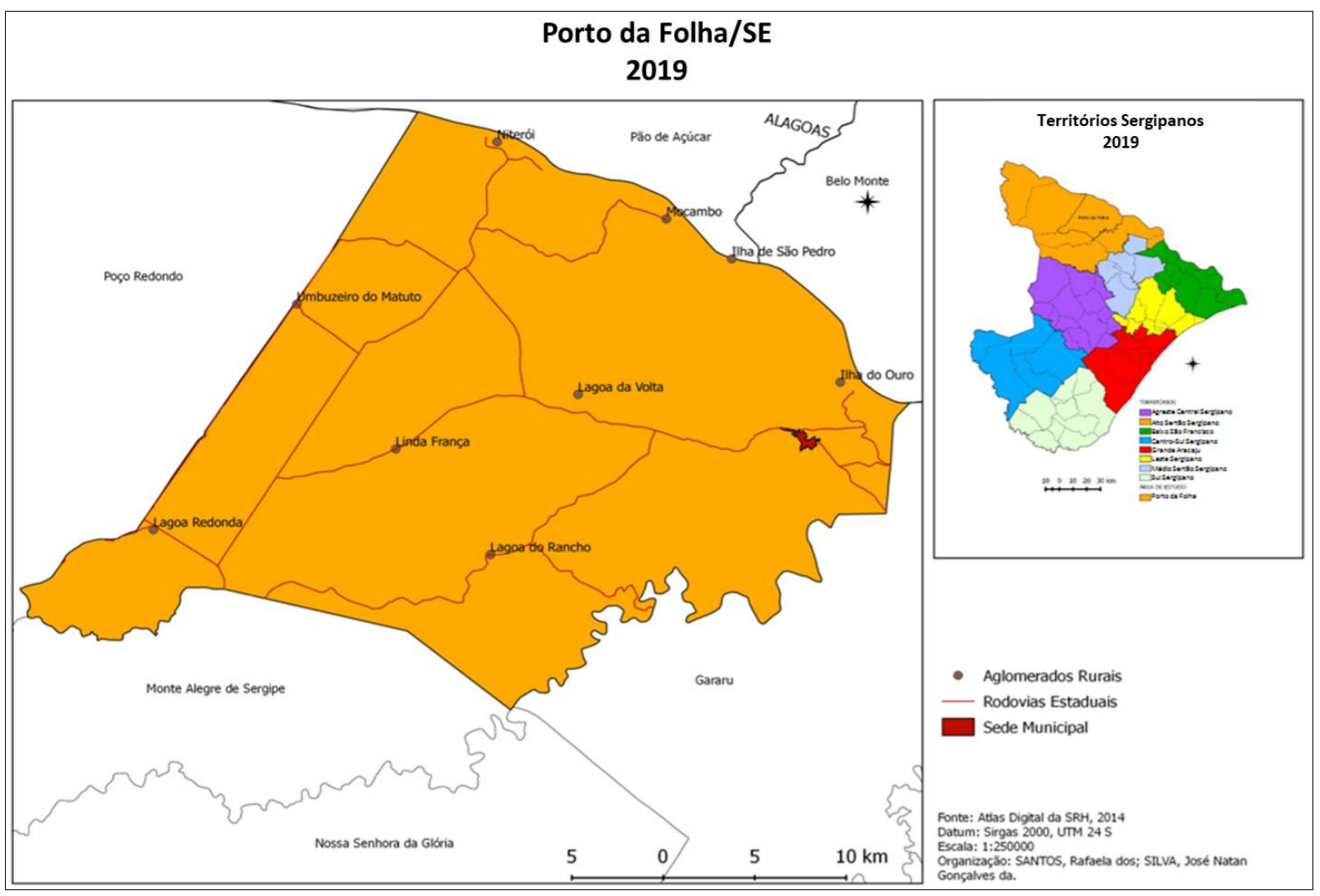

O predomínio da população residente no campo resulta da presença de aglomerados rurais $^{3}$ no interior do município, formados historicamente pelo desenvolvimento da pecuária bovina. Os dados do censo demográfico realizado pelo IBGE (2010) retratam que Porto da Folha possui nove aglomerados rurais: Lagoa da Volta, Lagoa Redonda, Lagoa do Rancho, Linda França, Ilha do Ouro, Niterói, Mocambo, Ilha de São Pedro e Umbuzeiro do Matuto, que totalizam 8.440 habitantes e 2.365 domicílios ${ }^{4}$.

A relevância do contingente populacional rural também se deve a implementação de projetos de assentamentos rurais a partir da década de 1980. Dados apontados pelo INCRA revelam que, até o ano de 2015 em Porto da Folha, 251 famílias foram beneficiadas com projetos de assentamentos rurais, que incorporavam uma área total de 5.905 hectares.

Essa dinâmica reflete-se na estrutura fundiária do município composta, principalmente, por minifúndios, pequenos e médios estabelecimentos. $O$ censo

\footnotetext{
${ }^{3} \mathrm{Na}$ metodologia de pesquisa utilizada pelo IBGE, as comunidades que têm 50 ou mais domicílios contíguos são classificadas como aglomerados rurais. As demais localidades são consideradas de povoamento disperso e não são contempladas com o recenseamento específico do núcleo rural.

${ }^{4}$ Segundo Santos e Andrade (1992), em alguns municípios de Sergipe, a distribuição populacional no campo partiu, consideravelmente, de uma forma dispersa para uma dinâmica acentuada e contígua, que desencadeou na formação de aglomerados rurais.
} 
agropecuário realizado pelo IBGE em 2017 retrata que o município possui 2.647 estabelecimentos agropecuários (Tabela 1), mantidos, predominantemente, por agricultores de base familiar.

TABELA 1: ESTRUTURA FUNDIÁRIA ${ }^{5}$ - PORTO DA FOLHA/SE - 2017

\begin{tabular}{c|c|c}
\hline Grupos de área (ha) & $\begin{array}{c}\text { Número de } \\
\text { estabelecimentos } \\
\text { agropecuários (unid.) }\end{array}$ & $\begin{array}{c}\text { Área dos } \\
\text { estabelecimentos } \\
\text { agropecuários (ha) }\end{array}$ \\
\hline Total & 2.647 & 56.698 \\
Menos de 1 & 199 & 119 \\
1 a menos 5 & 545 & 1.503 \\
5 a menos 10 & 546 & 4.087 \\
10 a menos 20 & 618 & 8.811 \\
20 a menos 50 & 497 & 15.173 \\
50 a menos 100 & 170 & 12.141 \\
100 a menos 200 & 43 & 5.866 \\
200 a menos 500 & 24 & 6.632 \\
500 a menos 1.000 & 4 & $X$ \\
1.000 a menos 2.500 & - & - \\
2.500 a menos 10.000 & - & - \\
10.000 e mais & - & $X$ \\
Produtor sem área & 1 & - \\
\hline
\end{tabular}

Fonte: IBGE - Censo agropecuário, 2017.

Org. GONÇALVES DA SILVA, J. N. 2019.

Apesar de configurar uma estrutura fundiária, relativamente, marcada pela pequena e média propriedade rural, a agropecuária do município de Porto da Folha é dinamizada pelo uso de insumos e pacotes tecnológicos, até recentemente, restritos ao agronegócio. Esse impacto se deve a atuação das grandes corporações vinculadas ao agrobusiness, que organizam e induzem os sistemas de produção, comercialização e consumo que, inclusive, são reproduzidos in loco.

Nesse sentido, os agricultores familiares são sujeitados a modelos produtivos padronizados, algo que compromete a legitimidade do grupo que, não raro, perde a autonomia de produzir seus próprios alimentos, necessários à reprodução socioeconômica e cultural da família.

Em benefício das prerrogativas do mercado estimula-se um modelo de desenvolvimento excludente, que fragiliza a diversidade produtiva das comunidades

\footnotetext{
${ }^{5}$ Conforme nota do IBGE são desidentificados com o caractere $X$ as unidades territoriais com número insuficiente de informantes. Diante disso, pode haver discrepância entre área total dos estabelecimentos e o somatório da área dos estabelecimentos considerando individualmente os grupos de área.
} 
tradicionais e das unidades de produção familiar, em favorecimento às cadeias de monoculturas, em larga escala, financiadas pelo agronegócio ${ }^{6}$.

A modificação da base tecnológica dos sistemas agroalimentares constitui um processo intrínseco às transformações do espaço rural brasileiro. Para tanto, denota-se que as unidades de produção familiar também estão imersas nessas mudanças.

Apesar da modernização conservadora no Brasil que restringiu inicialmente 0 acesso de tecnologias agrícolas modernas as grandes propriedades e corporações vinculadas aos agribusiness, na década de 1990 e, consideravelmente, nas décadas de 2000 e 2010, os recursos tecnológicos agropecuários estiveram acessíveis a segmentos da agricultura familiar mediante 0 incentivo de empreendimentos privados e das políticas de crédito - e mesmo as assistenciais -, elaboradas pelo Estado. A especialização produtiva da agricultura familiar via proteção e incentivo assistencial e crediário a preços mínimos tem sido um comportamento firmado pelas agências governamentais e privadas, que interagem com os programas de reforma agrária e as redes de produtores rurais.

No município de Porto da Folha, as transformações das relações produtivas no campo estão associadas às modificações na cadeia da bovinocultura leiteira, alinhando-se ao desenvolvimento econômico dos sertões no Nordeste brasileiro que, predominantemente, esteve atrelado à pecuária bovina ${ }^{7}$.

A princípio essa atividade caracterizava-se pela dinâmica extensiva e de baixa rentabilidade, mas, posteriormente apresenta ciclos de desenvolvimento associados a especializações produtivas decorrentes do melhoramento genético dos animais (introdução de bovinos da raça zebu e matrizes de vacas holandesas) e incremento na alimentação da palma forrageira (Opuntia fícus indica- Mill).

A partir da década de 1980 o desenvolvimento da pecuária leiteira no sertão de Sergipe está vinculado à estruturação de um sistema agroalimentar localizado (SIAL) constituído por laticínios, fabriquetas de produtos derivados do leite e queijarias artesanais especializadas na produção de queijo coalho ${ }^{8}$.

\footnotetext{
${ }^{6}$ A despeito dessa abordagem, Rojas (2003, p.85) é enfático ao mencionar que a "globalização não respeita nenhum limite, no afã de converter todos os habitantes do planeta em consumidores dos produtos elaborados pelas companhias multinacionais".

7 Para ampliar o debate ver: ANDRADE, Manuel Correia de. A terra e o homem no Nordeste: contribuição ao estudo da questão agrária no Nordeste. 7. ed. São Paulo: Cortez, 2005.

8 Conforme Menezes (2009) a ampliação da produção agroalimentar dos derivados de leite se deve ao aumento da procura desses alimentos pelos migrantes originários do sertão e residentes nos centros urbanos, que demandam os produtos referenciados no seu território de origem.
} 
O protagonismo histórico do sertanejo associado à pecuária e os estímulos à produção leiteira no sertão de Sergipe fomentaram readaptações nos sistemas produtivos da agricultura familiar traduzidos na melhoria das pastagens, na certificação e cuidados à sanidade dos animais, no uso de ordenhadeiras mecânicas, na realização de duas ordenhas diárias e no uso de rações a base do milho forrageiro na dieta nutricional dos rebanhos.

Durante diferentes temporalidades a palha, o farelo e o xerém de milho estiveram inseridos na composição alimentar dos bovinos, mas a elaboração do silo e do rolão ${ }^{9}$ constituem técnicas até recentemente desconhecidas pelos agricultores. O procedimento é uma alternativa que reduz a dependência pela soja e diminui os entraves dos produtores rurais diante da escassa disponibilidade de alimento para os bovinos durante as constantes estiagens. A produção das rações foi incentivada inicialmente por técnicos agropecuários provenientes de órgãos públicos (EMBRAPA e EMDAGRO) e instituições bancárias (Banco do Brasil e Banco do Nordeste do Brasil) junto a associações de agricultores.

O milho, considerado um alimento com valor de uso, voltado, predominantemente para a alimentação das famílias rurais e presente em diversas combinações nutricionais (milho cozido, pamonha, canjica, fubá, bolo, mungunzá e cuscuz), adquiriu também uma valoração produtiva orientada à elaboração de silagem para o desenvolvimento da bovinocultura leiteira.

Nesse contexto, a produção do milho sobrepôs-se a outros cultivos inseridos na dieta nutricional e na cultura agroalimentar do sertanejo. Dados disponíveis na tabela 2 e no gráfico 1 denotam que, o estímulo ao monocultivo do milho forrageiro em Porto da Folha reduziu a participação dos agroecossistemas cultiváveis do feijão e da mandioca na quantidade produzida de alimentos da lavoura temporária.

TABELA 2: PRODUTOS DA LAVOURA TEMPORÁRIA - PORTO DA FOLHA/SE 1995-2017

\begin{tabular}{c|c|c|c}
\hline \multirow{2}{*}{ Produtos Agrícolas } & \multicolumn{3}{|c}{ Ano } \\
\cline { 2 - 4 } & $\mathbf{1 9 9 5}$ & $\mathbf{2 0 0 6}$ & $\mathbf{2 0 1 7}$ \\
\hline Milho forrageiro & 4.664 & 2.193 & 97.845 \\
Milho em grão & 5.708 & 3.247 & 1.717 \\
Feijão em grão & 2.354 & 943 & 93 \\
Mandioca & 628 & 22 & 16 \\
\hline
\end{tabular}

Fonte: IBGE - Censo agropecuário, 1995, 2006 e 2017.

Elaboração: GONÇALVES DA SILVA, J. N; MENEZES, S. S. M. 2019.

\footnotetext{
${ }^{9}$ A diferença entre as rações silo e rolão consiste no fato da primeira ser produzida com o milharal verde, "vivo", enquanto a segunda é elaborada com a planta e o grão secos.
} 


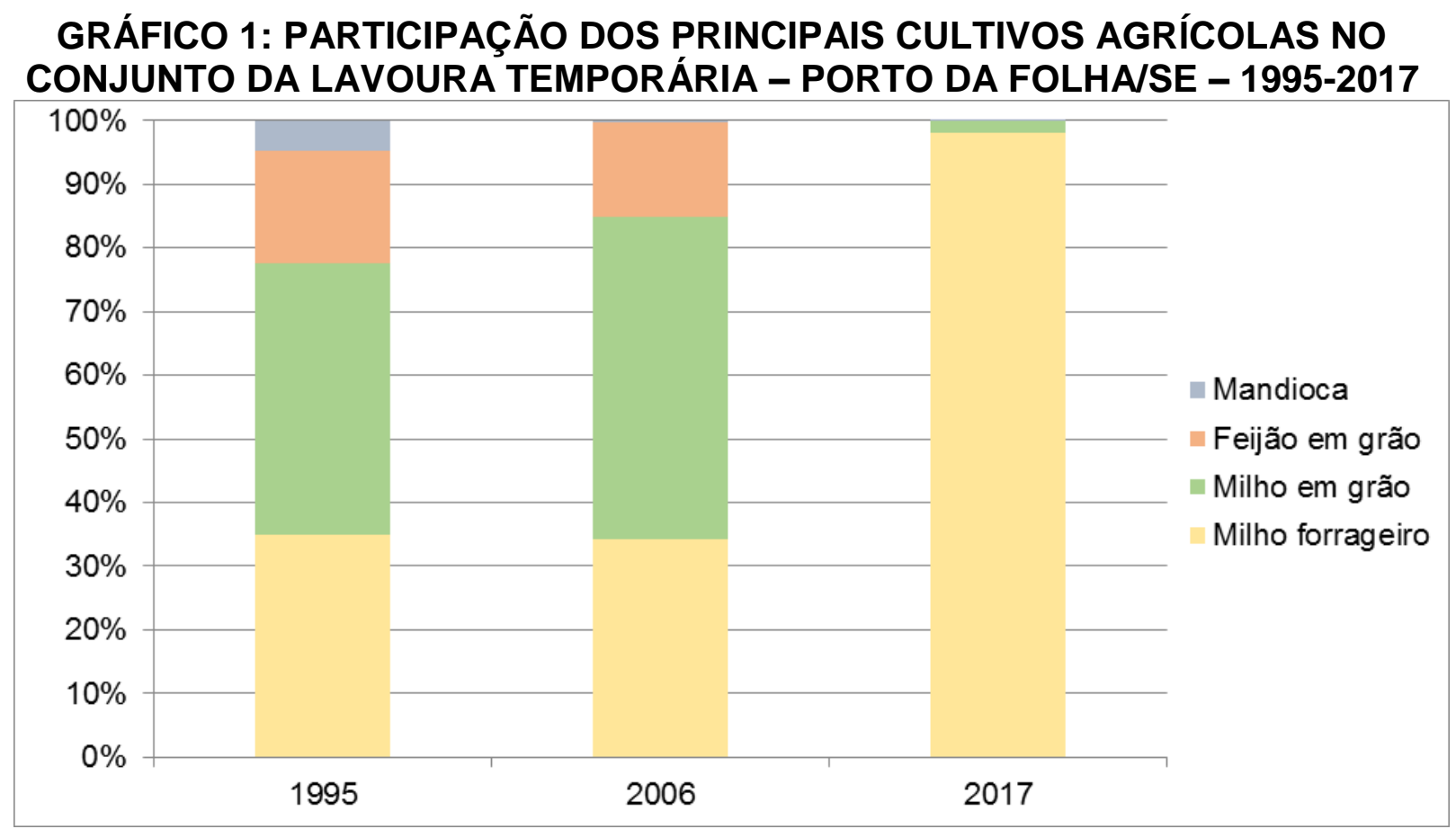

Fonte: IBGE - Censo agropecuário, 1995, 2006 e 2017.

Elaboração: GONÇALVES DA SILVA, J. N; MENEZES, S. S. M. 2019.

As estatísticas então levantadas no censo agropecuário de 1995 apontam que a produção agrícola do município já apresentava o domínio do milho. Tal fato se deve a importância que esse gênero assume na base alimentar do sertanejo e na dieta nutricional dos animais domesticados, sobretudo, os bovinos, os equinos, os suínos e as aves. Os dados também retratam a participação relevante das lavouras de feijão e de mandioca dentre os cultivos agrícolas, que traduziam a configuração da diversidade agroalimentar da agricultura de base familiar.

Todavia, o crescimento significativo dos cultivos de milho forrageiro, apontado pelo censo agropecuário de 2017, praticamente suplanta a produção dos demais gêneros agroalimentares. Este cenário também não garante a participação do "milho da roça" e de seus derivados na mesa do lavrador, tendo em vista, que a produção do grão está voltado, principalmente, ao abastecimento da alimentação de rebanhos de bovinos que, por sua vez, sustentam o fortalecimento da pecuária leiteira ${ }^{10}$.

Até meados da década de 1990, a produção agrícola do município estava, predominantemente, estruturada na policultura consorciada, cujos principais produtos da lavoura, o milho (nas variações crioulas: grão de ouro, branco, alho e ligeirinho), e o feijão, (nas variantes boca-funda, mulatão, mulatinho, roxinho e corda

10 Menezes (2013) menciona que a modernização do campo prenunciou a tendência de homogeneização da agricultura. Destarte, notou-se que diversos produtos agrícolas perderam suas características específicas e passaram a ser considerados commodities. Esse processo também atinge os agricultores familiares, sobretudo os segmentos integrados ao mercado. 
ou fradinho), eram cultivados no período das chuvas (março a julho), juntamente com outros gêneros agrícolas inseridos na dieta alimentar do sertanejo: mandiocabrava, macaxeira, fava, quiabo, maxixe, melão, melancia e abóbora. Eram períodos de "grandeza" em que, "caso a chuva viesse, a mesa era farta".

O lavrador ciente da possível ocorrência da estiagem reservava parte do alimento a ser consumido durante todo o ano. Sempre preparado para a ocorrência de chuvas, selecionava e resguardava as melhores sementes a serem cultivadas na próxima colheita ${ }^{11}$.

A organização produtiva e a diversidade alimentícia do sertanejo foi um dos sustentáculos do equilíbrio nutricional dos homens e mulheres que habitavam o sertão, garantindo-Ihes, inclusive, a convivência com o semiárido e o enfrentamento da política da seca. Todavia, a integração de segmentos da agricultura familiar à lógica de produção pautada no monocultivo do milho desestabilizou a diversidade agroalimentar no espaço rural.

Os agricultores entrevistados passam pelo processo de substituição dos meios de produção artesanais, por técnicas e insumos modernos. As práticas tradicionais de arado da terra por tração animal e a colheita manual constituem atividades suprimidas por maquinários (arados, colheitadeiras e ceifadeiras de forragem mecânicas). A limpeza da roça, outrora efetivada artesanalmente com o auxílio da enxada e, não raro, através de mutirões comunitários, atualmente é realizada de forma predatória com o uso de herbicidas, aplicados de forma insegura por meio de pulverizadores manuais e mecânicos. Também é intensiva a utilização de inseticidas, voltados para a eliminação de lagartas (Spodoptera frugiperda), que avançam numerosas sobre os cultivos de milho. O desequilíbrio ambiental é provocado pelo uso, sem precedentes, de agrotóxicos que eliminam as ervas naturais do campo, alimento desses insetos, bem como, pelo aumento da sua resistência ao envenenamento por inseticidas.

Dentre os agrotóxicos aplicados nas atividades da agropecuária, sobressaem Tordon, Glifosato, Atrazina e DMA empregados no controle de ervas indesejáveis nas pastagens e nos cultivos de palma e do milho, e Cypermil, Colosso e Barrage, utilizados no combate contra parasitas (moscas e carrapatos) nos bovinos e adaptados no combate de lagartas nos plantios de milho, procedimentos realizados sem orientações de profissionais de extensão rural.

${ }^{11}$ Castro (1984, p.176) menciona que a diversidade produtiva era uma característica marcante do sertanejo. O cultivo do milho estava associado a outros produtos regionais, permitindo-lhe, com exceção dos períodos da seca, perfeito equilíbrio alimentar e nutricional. 
Em decorrência da precariedade na manipulação dos agrotóxicos nota-se o comprometimento da saúde e da integridade física dos agricultores e das famílias rurais, que direta ou indiretamente, estão sujeitas aos efeitos danosos dos agroquímicos. A sua aplicação intensiva tem causado excessivos danos aos recursos naturais, como a degradação dos solos, perda de espécies vegetais e animais, poluição do ar e dos cursos fluviais.

Os impactos dos herbicidas nas plantações de milho (vegetal monocotiledôneo) implicam, predominantemente, na eliminação das "ervas daninhas" eudicotiledôneas e, consequentemente, tais agrotóxicos causam o envenenamento e a mortandade de cultivos agroalimentares como o feijão, a fava, a abóbora, o maxixe, o melão e a melancia. Desse modo, a aplicação dos defensivos químicos contribui para a redução das áreas de plantio consorciado, diminuindo a diversidade produtiva agroalimentar dos estabelecimentos dos agricultores familiares. Essa dinâmica prejudica a manutenção do material genético desses agroecossistemas, outrora difundidos no território pelos antigos povos que habitavam as terras do sertão.

Tal modelo produtivo está baseado nos princípios da Revolução Verde, que expõe a dependência entre a agricultura e a indústria de insumos. Aliado ao discurso político, financeiro e midiático difunde-se no sertão sergipano a incerta "viabilidade" produtiva dos OGMs ${ }^{12}$.

A transgenização da produção do milho, a quimificação das atividades agrícolas e a redução da policultura consorciada contribuíram para a diminuição dos bancos de sementes crioulas, tornando os agricultores dependentes das multinacionais produtoras de sementes.

É perceptível entre os agricultores a modificação dos hábitos alimentares em decorrência da adesão à produção agrícola dos insumos químicos, transgênicos e do fomento ao monocultivo do milho ${ }^{13}$. Reduz-se a prática de cultivar verduras, raízes, leguminosas e frutas, bens agrícolas que passam a ser adquiridos nas feiras livres realizadas semanalmente na sede do município e nos aglomerados rurais.

As casas de farinhas, espaços de sociabilidade, reciprocidade e difusão de saberes/fazeres relativos à elaboração das iguarias derivadas da mandioca: tapioca,

12 Mittal e Peter (2003) retratam que as grandes corporações transnacionais vinculadas ao agronegócio atuam na criação de falsos sentimentos mediante campanhas publicitárias, que transmitem as duvidosas viabilidades econômica, social e ambiental da utilização dos transgênicos.

${ }^{13}$ A despeito dessas mudanças, Menezes (2013) enfatiza a força dos conglomerados industriais na transformação das práticas alimentares e dos modos de produção, armazenamento e seleção das sementes, banindo das comunidades tradicionais produtos enraizados no território. 
farinha, massa puba, beiju, saquarema, mal casado, pé-de-moleque e bolo de puba, passam a configurar rugosidades dispersas nos territórios rurais diante da redução do cultivo da mandioca. Assim como as frutas, hortaliças e leguminosas, esses alimentos passam a ser adquiridos de feirantes provenientes do agreste sergipano.

O feijão, cuja semeadura era realizada nas roças de cultivos consorciados, gradativamente passa a ser obtido em supermercados, que estão articulados às agroindústrias beneficiadoras de alimentos. O descompasso entre a redução da oferta e a manutenção da demanda, por um alimento ainda intrínseco à cultura alimentar do sertanejo, contribui para que esse gênero agrícola apresente uma volatilidade no valor de mercado. No ano de 2016, diante da ocorrência de estiagem e deficiência hídrica nas grandes áreas produtoras e distribuidoras do grão no sertão baiano, Irecê e Ribeira do Pombal, o feijão atingiu no semiárido sergipano cifras de $R \$ 20,00$ o quilograma, fato que comprometeu a presença desse alimento na mesa de agricultores e consumidores.

Essas mudanças tornam escassos os hábitos atrelados ao manejo e à manipulação do feijão que, comumente, eram observados no cotidiano das comunidades rurais. Não se verifica com a mesma frequência do passado, mulheres sentadas nas calçadas, aos finais de tarde, debulhando o grão maduro, nem tampouco a prática coletiva de "bater ou xaxar o feijão ${ }^{14 "}$ e o costume de secá-lo ao sol para, posteriormente, ser reservado e estocado.

Alterações também são observadas no tocante ao consumo de comidas derivadas do milho. No período da colheita, no mês de São João ${ }^{15}$ e, de modo significativo, nos festejos juninos, as mulheres elaboram nas cozinhas sertanejas as diversas variedades de iguarias derivadas do milho. Entretanto, o uso dos grãos híbrido e transgênico, em substituição às sementes crioulas, modifica o sabor das comidas e dos quitutes: trata-se de um discurso presente na fala dos agricultores ao afirmarem que "o milho perdeu o doce"; "a canjica e a pamonha de hoje não tem mais o mesmo gosto"; ou simplesmente "não se faz mais um cuscuz de milho novo como antes".

$\mathrm{Na}$ alimentação das famílias rurais também foi fragmentado o antigo costume de reservar parcela das espigas para a elaboração caseira da massa de milho. $\mathrm{Na}$ sua elaboração estavam incluídas técnicas artesanais que se tornaram raras:

\footnotetext{
${ }^{14}$ Ato de debulhar o feijão com o auxílio de paus e varas de madeira, cujos golpes auferidos nas ramas do feijoeiro seco permitem a separação da bage (vagem) e do grão.

15 Os agricultores tradicionais denominam de São João, o mês de junho. Trata-se de uma homenagem simbólica ao principal santo junino. Fato semelhante ocorre com o mês de julho, denominado Santana para homenagear Sant'Ana, cuja festa é realizada no mês de julho.
} 
praticamente não se utiliza mais o pilão de madeira, o moinho de xerém ou o ralo de ferro para triturar e fazer a massa de milho.

Destituído dos seus meios de produção, mas buscando manter a essência cultural dos seus hábitos alimentares, o sertanejo adere ao consumo de cuscuz à base de flocos de milho produzidos por agroindústrias nacionais. Trata-se de uma ruptura na relação que os agricultores mantêm com o seu meio, com a produção agrícola e com as inúmeras tarefas associadas à manipulação dos alimentos ${ }^{16}$.

Tais mudanças pressionam ressignificações nos hábitos alimentares e no saber/fazer inerente as escolhas nutricionais enraizadas na culinária dos grupos sociais. Os gêneros alimentícios industrializados, dotados de composição nutricional significativamente artificializada, passam a compor a comida servida na mesa do agricultor, não raro com ingredientes alheios à culinária local, que resultam em combinações alimentares com cheiros, cores, consistências e sabores relativamente padronizados.

No âmbito do beneficiamento agroindustrial do milho, deve-se destacar a atuação de agricultores familiares da Associação de Desenvolvimento Comunitário do Povoado Lagoa da Volta, que fundaram a Fábrica Santa Luzia, onde é realizada a produção de flocos de milho. As atividades desempenhadas têm como finalidade realizar o beneficiamento do milho de membros da associação e agricultores locais que, não raro comercializavam seu produto a preço mínimo no mercado de insumos agrícolas. Todavia, considerável parcela da matéria-prima é proveniente de outros municípios do sertão e do agreste sergipano, predominantemente, grãos produzidos com sementes transgênicas.

O protagonismo dos associados no estabelecimento da fábrica contribuiu para a constituição de uma estratégia coletiva de geração de renda para os agricultores. Por sua vez, vale ressaltar que a substituição do milho transgênico por grãos crioulos ou provenientes de processos produtivos sustentáveis, poderia fomentar a agregação de valor à farinha de milho Santa Luzia.

Partindo desses pressupostos foram identificados durante as entrevistas agricultores ligados a movimentos, associações e assentamentos rurais, que se contrapõem ao discurso da quimificação e transgenização do processo produtivo e desenvolvem práticas fundamentadas no trabalho coletivo, na difusão de saberes na convivência com o semiárido e na propagação do paradigma da agroecologia. Tais

\footnotetext{
${ }^{16}$ Arnaiz (2005) contribui com essa discussão ao mencionar que esse processo está fundamentado na industrialização da agricultura, que deslocou as funções de produção, conversação e preparo dos alimentos do âmbito doméstico e artesanal para as indústrias.
} 
experiências foram identificadas na Associação de Mulheres do Povoado Lagoa da Volta e nos Assentamentos José Unaldo de Oliveira, Paulo Freire e Nossa Senhora da Conceição.

A produção agroecológica tem como foco o manejo de ecossistemas cultiváveis, baseados em mecanismos que assegurem a preservação dos recursos naturais e que sejam culturalmente sensíveis aos saberes dos agricultores e possibilitem a reprodução socioeconômica das famílias rurais. Esse modelo garante à agricultura familiar vantagem comparativa quando relacionada à agricultura empresarial ${ }^{17}$.

Os produtores agroecológicos, vinculados aos assentamentos rurais, realizam cultivos diversificados com predomínio de frutas, raízes, verduras, hortaliças e legumes. Destaca-se ainda a produção artesanal de origem animal: leite, queijo coalho, galinhas e ovos de capoeira ${ }^{18}$. A "feira da agricultura familiar", realizada na sede do município, consiste a principal alternativa de mercado desses produtores e referencia-se entre os consumidores pelo compromisso na comercialização de alimentos saudáveis e ecologicamente corretos.

As mulheres associadas ostentam como resultado do seu trabalho a garantia da soberania alimentar das suas famílias. $O$ excedente dos produtos é comercializado diretamente aos consumidores das comunidades locais e circunvizinhanças. Além do cultivo de hortaliças, verduras e legumes, elas realizam a produção de mel de abelha e de doces (balas de banana e geleia) elaborados em uma cozinha semi-industrial. Com a finalidade de preservar a cultura e a diversidade do patrimônio genético dos recursos cultiváveis do território, as integrantes realizam a seleção e a construção de um banco de sementes. No tocante ao trabalho ambiental, desenvolvem com jovens da comunidade a produção de mudas de árvores para reflorestamento de áreas da caatinga e arborização de vias e espaços públicos.

Logo, apesar do domínio de atividades agrícolas regidas pela modernização/padronização dos cultivos, consideram-se relevantes as experiências embasadas em modelos agroalimentares alternativos desenvolvidos por agricultores e agricultoras familiares. Além de fomentarem o uso sustentável dos recursos naturais e contribuírem na garantia da segurança alimentar de consumidores e suas

\footnotetext{
${ }^{17}$ Conforme Altieri (2004), a agroecologia está pautada na perspectiva biossistêmica e de diversidade produtiva, que não se adéqua ao modelo produtivo defendido pelo agronegócio, ancorado no esgotante uso dos recursos naturais e na busca constante pela produtividade e pelo lucro.

${ }_{18}$ Menezes e Cruz (2017) retratam que esses alimentos tradicionais são considerados manifestações culturais e a sua comercialização contribui para a reprodução social dos agricultores.
} 
famílias, as práticas estimulam a difusão do pensamento, que se contrapõe à lógica da modernização pautada no incerto paradigma da Revolução Verde e que está voltado para a retroalimentação do capital acumulado pelas transnacionais, que dominam o mercado de insumos e gêneros alimentícios.

\section{Considerações Finais}

A modernização da produção agroalimentar, pautada no uso intensivo de insumos, causou elevados danos aos bens ecológicos, à seguridade de uma alimentação saudável e à garantia da soberania alimentar aos produtores rurais. Trata-se de transformações nas relações produtivas, que destituem os agricultores dos seus meios de produção e corrompem seu protagonismo perante a reprodução das suas atividades agrícolas tradicionais.

O caminho traçado pelos agricultores familiares do município de Porto da Folha/SE - recorte empírico de uma realidade dominante no sertão sergipano -, revela o futuro incerto no tocante à conservação dos recursos naturais, à autossuficiência produtiva e alimentar e à preservação da multiculturalidade intrínseca no modo de vida, no trabalho na terra, na diversidade agrícola e nos atos de escolher, manipular e consumir os alimentos.

A manutenção dos diversos agroecossistemas cultiváveis encontra-se ameaçada pelos incentivos à padronização do processo produtivo, vinculados ao monocultivo do milho. Os agricultores estão embalados pelos estímulos do marketing e pelos discursos político, midiático e dos agentes financeiros, que defendem a modernização como o único mecanismo de ascensão econômica e empoderamento. Todavia, tal conjuntura retrata os reais interesses dos atores hegemônicos em garantir o prodigioso expansionismo das corporações transnacionais vinculadas ao agronegócio, que dominam em escala mundial o mercado de sementes, insumos agropecuários e que estão aliadas às multinacionais do setor alimentício.

Diante desse cenário, verifica-se a gradativa redução e a perda de sementes crioulas difundidas no território, patrimônio genético e cultural que outrora foi selecionado, conservado e repassado pelas antigas gerações, por meio das redes de sociabilidade. As escolhas e os hábitos alimentares das famílias rurais foram modificados. Produtos agrícolas ou semielaborados, não mais produzidos e reservados nos estabelecimentos rurais, são adquiridos nas redes de 
supermercados que, por sua vez, são abastecidos por agroindústrias e distribuidoras de alimentos. Novas necessidades também são criadas pela sociedade de consumo e, contraditoriamente, produtos alimentícios alheios à cultura alimentar dos agricultores são inseridos na sua dieta nutricional.

Bens agrícolas como hortaliças, leguminosas, frutas e verduras, além de iguarias, como os derivados da mandioca, são adquiridos nas feiras livres. Essa prática denota a manutenção da identidade alimentar, mesmo diante das mudanças em curso. Outros produtos, como os derivados do milho, cuja matéria-prima é originária de sementes híbridas e geneticamente modificadas, não apresentam a combinação de sabores e cheiros apreciados no passado.

Apesar do contexto reportado, é imprescindível que segmentos e movimentos políticos e sociais, vinculados a modelos alternativos de produção, propaguem suas ideias e experiências bem-sucedidas. O enfrentamento dos atores hegemônicos que dominam a produção de insumos e alimentos se faz necessário.

É significativo o crescimento de produtores e consumidores em territórios rurais e urbanos atentos ao consumo de alimentos saudáveis. O sucesso das práticas agrícolas pautadas no associativismo e aliadas à convivência com o semiárido, bem como as feiras agroecológicas, mantidas por agricultores e agricultoras familiares, demonstram a tomada de consciência de parcela da sociedade acerca da importância do consumo de gêneros agrícolas, cujo modelo produtivo esteja comprometido com a qualidade de origem do produto, a redução do consumo de insumos e com o uso sustentável dos recursos naturais.

\section{REFERÊNCIAS}

ALTIERI, Miguel. Agroecologia: a dinâmica produtiva da agricultura sustentável. 4. ed. Porto Alegre: Editora da UFRGS, 2004.

ANDRADE, Manuel Correia de. A terra e o homem no Nordeste: contribuição ao estudo da questão agrária no Nordeste. 7. ed. São Paulo: Cortez, 2005.

ANJOS, Flávio Sacco dos; CALDAS, Nádia Velleda. Uma resposta sólida a um regime agroalimentar em crise: o fenômeno GAS na Itália. Revista Brasileira de Ciências Sociais, n. 95, v. 32, p. 01-19, 2017. Disponível: <http://www.scielo.br/pdf/rbcsoc/v32n95/1806-9053rbcsoc-3295132017.pdf>. Acesso: 05 jan. 2018.

ARNAIZ, Mabel Gracia. Em direção a uma Nova Ordem Alimentar? In: CANESQUI, Ana Maria; GARCIA, Rosa Wanda Diez. Antropologia e nutrição: um diálogo possível. Rio de Janeiro: Editora FIOCRUZ, 2005, p. 147-166. 
BOUCHER, François. Agroindustria rural y sistemas agroalimentarios locales. Nuevos enfoques de desarrollo territorial. In: III Congreso Internacional de la Red SIAL "Sistemas Agroalimentarios locales”, Alimentación y Territorios, 2006, Baeza (Jaén) - España. Anais. Baeza (Jaén), España: Universidad Internacional de Andalucía/ALTER, 2006, p.1-23.

BRANDÃO, Carlos Rodrigues. Tempos e espaços nos mundos rurais do Brasil. Ruris, v.1, n.1, p.37-64, mar. 2007.

CASTRO, Josué de. Geografia da fome: o dilema brasileiro: pão ou aço. 10. ed. Rio de Janeiro: Edições Antares, 1984.

CAVALCANTI, Josefa Salete Barbosa. Globalização e ruralidade. In: WANDERLEY, Maria de Nazareth Baudel. Globalização e desenvolvimento sustentável: dinâmicas sociais rurais no Nordeste brasileiro. Campinas/SP: Ceres, 2004. p.17-32.

COSTA, Manoel Baltasar Baptista da. Recursos genéticos, sustentabilidade e segurança alimentar. In: CARVALHO, Horacio Martins. Sementes: patrimônio do povo a serviço da humanidade. São Paulo: Expressão Popular, 2003, p. 323-341.

FRIEDMANN, Harriet. The Political Economy of Food: The Rise and Fall of the Postwar International Food Order. American Journal of Sociology, Chicago, v. 88, p. S248-S286, 1982.

GRAZIANO DA SILVA, José. Progresso técnico e relações de trabalho na agricultura. São Paulo: Hucitec, 1981.

GRAZIANO DA SILVA, José. A nova dinâmica da agricultura brasileira. 2. ed. rev. Campinas/SP: UNICAMP, 1998.

GRAZIANO DA SILVA, José. Tecnologia e Agricultura Familiar. Porto Alegre: Ed. Universidade/UFRGS, 1999.

IANNI, Octavio. A era do globalismo. 3 ed. Rio de Janeiro: Civilização Brasileira, 1997.

IBGE. Instituto Brasileiro de Geografia e Estatística. Censo demográfico 2010 e Censo agropecuário 1995, 2006 e 2017. Disponível: <www.ibge.gov.br>. Acesso: dez. 2018.

INCRA. Projetos de Reforma Agrária. Disponível: <www.incra.gov.br>. Acesso: 23 dez. 2018.

MARAFON, Glaúcio José. Principais transformações em curso no espaço rural na atualidade. Revista Geográfica de América Central, Número Especial, p.69-84, 2011.

MATOS, Patrícia Francisca; PESSÔA, Vera Lúcia Salazar. A modernização da agricultura no Brasil e os novos usos do território. Geo UERJ, Ano 13, no. 22, v. 2, p. 290-322, 2011.

MENEZES, Sônia de Souza Mendonça. A força dos laços de proximidade na tradição e inovação no/do Território Sergipano das Fabriquetas de Queijo. 2009. 359f. Tese (Doutorado em Geografia) - Núcleo de Pós-Graduação em Geografia. Universidade Federal de Sergipe, São Cristóvão, SE, 2009.

MENEZES, Sônia de Souza Mendonça. Comida de ontem, comida de hoje. O que mudou na alimentação das comunidades tradicionais sertanejas? OLAM - Ciência e Tecnologia, Ano 13, v. 1, n. 2, p.31-58, jul/dez. 2013.

MENEZES, Sônia de Souza Mendonça; CRUZ, Fabiana Thomé da. Alimentos tradicionais como manifestação cultural na contemporaneidade. In: MENEZES, Sônia de Souza 
Mendonça; CRUZ, Fabiana Thomé da (Orgs.). Estreitando o diálogo entre alimentos, tradição, cultura e consumo. São Cristóvão: Editora da UFS, 2017. p. 25-44.

MITTAL, Anuradha; ROSSET, Peter. Engenharia genética e privatização das sementes: avanço corporativo promove protesto global. In: CARVALHO, Horacio Martins. Sementes: patrimônio do povo a serviço da humanidade. São Paulo: Expressão Popular, 2003, p. 7384.

MORAES, Jorge Luiz Amaral de. O papel dos Sistemas e Cadeias Agroalimentares e Agroindustriais na formação das aglomerações produtivas dos territórios rurais. Revista do Desenvolvimento Regional - Faccat, n. 1, v. 10, p.71-97, jan./jun. 2013.

MOREIRA, Roberto José. Cultura, política e o mundo rural na contemporaneidade. Estudos Sociedade e Agricultura, 20, p.113-143, abril 2003.

RAMOS, Vitória de Paula. A abordagem de sistemas agrolimentares localizados (SIAL) e sua tradução conceitual e institucional na América Latina e Brasil. 2018. 208 f. Dissertação (Mestrado em Ciências Sociais) - Programa de Pós-graduação de Ciências Sociais em Desenvolvimento, Agricultura e Sociedade, Universidade Federal Rural do Rio de Janeiro, Rio de Janeiro, 2018.

ROJAS, Aldo Gonzáles. A contaminação com transgênicos dos milhos nativos, em Serra Juárez de Oaxaca, no México. In: CARVALHO, Horacio Martins. Sementes: patrimônio do povo a serviço da humanidade. São Paulo: Expressão Popular, 2003, p. 85-94.

SANTOS, Adelci Figueiredo; ANDRADE, José Augusto. Delimitação e regionalização do Brasil semi-árido - Sergipe. Aracaju: UFS, 1992.

VINUTO, Juliana. A amostragem em bola de neve na pesquisa qualitativa: um debate em aberto. Temáticas, Campinas/SP, v. 22, n. 44, p. 203-220, ago/dez. 2014.

\section{NOTAS DE AUTOR}

\section{CONTRIBUIÇÃO DE AUTORIA}

José Natan Gonçalves da Silva - Concepção. Coleta de dados, análise de dados, elaboração da primeira versão do manuscrito, revisão e aprovação da versão final do trabalho.

Sônia de Souza Mendonça Menezes - Concepção. Participação ativa da discussão dos resultados, elaboração da segunda versão do manuscrito, revisão e aprovação da versão final do trabalho.

\section{FINANCIAMENTO}

José Natan Gonçalves da Silva foi bolsista de mestrado e a pesquisa teve como agência de fomento a Coordenação de Aperfeiçoamento de Pessoal de Nível Superior - CAPES.

\section{CONSENTIMENTO DE USO DE IMAGEM}

Não se aplica.

\section{APROVAÇÃO DE COMITÊ DE ÉTICA EM PESQUISA \\ Não se aplica.}

\section{CONFLITO DE INTERESSES}

Não se aplica.

\section{LICENÇA DE USO}

Este artigo está licenciado sob a Licença Creative Commons CC-BY. Com essa licença você pode compartilhar, adaptar, criar para qualquer fim, desde que atribua a autoria da obra. 